\title{
Continuous Adductor Canal Block used for postoperative pain relief after medial Unicondylar Knee Arthroplasty: a randomized, double-blind, placebo- controlled trial
}

Fei Lan', Yanyan Shen², Yanhui Ma', Guanglei $\mathrm{CaO}^{3}$, Nicole Philips ${ }^{4}$, Ting Zhang ${ }^{1}$ and Tianlong Wang ${ }^{1 *}$ (D)

\begin{abstract}
Background: Peripheral nerve block and local infiltration analgesia (LIA) provide good analgesia after knee replacement. This study evaluated the additional analgesic efficacy of continuous adductor canal block (ACB) added to single-dose LIA after medial unicondylar knee arthroplasty (UKA). We hypothesized ACB would lower pain scores and facilitate postoperative ambulation.

Methods: Forty-six patients were enrolled into this double-blind, randomized, placebo-controlled trial. UKA was performed and all patients received single-dose LIA intraoperatively. Patients were randomized into two groups: Group RP receiving 0.2\% ropivacaine or Group Con receiving normal saline. A flow at $6 \mathrm{~mL} / \mathrm{h}$ was administered for $48 \mathrm{~h}$ through a catheter in the adductor canal. Primary outcome was movement pain score at $24 \mathrm{~h}$ using the numeric rating scale (NRS-11). Secondary outcomes included serial postoperative pain scores, rate of patients with NRS $>3$ at rest and movement within 24 and $48 \mathrm{~h}$ postoperatively, time to breakthrough pain, quadriceps motor strength, ambulated distance, catheter related infection and patient satisfaction.
\end{abstract}

Results: Forty-two patients were analyzed. Pain scores with movement at $24 \mathrm{~h}$ postoperatively were significantly lower in Group RP than that in Group Con (3 vs. 5 NRS, P<0.001). Compared with Group Con, breakthrough pain occurred later in Group RP (18.5 vs $10.0 \mathrm{~h}, P=0.002)$, serial pain scores at rest and with movement and rate of patients with NRS $>3$ with movement after surgery were significantly lower. Quadriceps motor strength was equivalent, however, ambulated distance on postoperative day 1 and 2 in Group Con was significant less (19.7 vs $37.3 \mathrm{~m}, P=0.046 ; 33.4$ vs $59.5 \mathrm{~m}, P=0.002)$.

Conclusions: Continuous adductor canal block added to single-dose LIA offered better analgesia and facilitated ambulation without motor weakness after medial UKA.

Trial registration: Clinical Trial Registration: ChiCTR-IOR-16008720; Registered 25 June 2016.

Keywords: Knee, Arthroplasty, Adductor canal block, Local, Analgesia

\footnotetext{
* Correspondence: w_t15595@hotmail.com

'Department of Anesthesiology Xuanwu Hospital, Capital Medical University,

No.45, Changchun Street, Beijing 100053, China

Full list of author information is available at the end of the article
}

(c) The Author(s). 2019 Open Access This article is distributed under the terms of the Creative Commons Attribution 4.0 International License (http://creativecommons.org/licenses/by/4.0/), which permits unrestricted use, distribution, and reproduction in any medium, provided you give appropriate credit to the original author(s) and the source, provide a link to the Creative Commons license, and indicate if changes were made. The Creative Commons Public Domain Dedication waiver (http://creativecommons.org/publicdomain/zero/1.0/) applies to the data made available in this article, unless otherwise stated. 


\section{Background}

Similar to total knee arthroplasty (TKA), moderate to severe pain caused by surgical trauma and early functional rehabilitation is anticipated after medial unicondylar knee arthroplasty (UKA) [1]. Optimal pain management, while minimizing analgesia-related complications is imperative, as pain after UKA can largely affect early ambulation, rehabilitation, and discharge [2]. Multimodal analgesic regimens, which include pain medications, local infiltration anesthesia (LIA) and peripheral nerve blocks (PNB), may be the most effective way of managing pain after major joint arthroplasty [3, 4]. While each regimen works well following TKA, femoral nerve blockade (FNB) has traditionally been the gold standard for analgesia [5]. The major disadvantages to FNB include, short duration and muscle strength reduction, and as a result, an alternative method is required [6, 7]. Recently, adductor canal block (ACB) has been suggested to be an alternative to FNB and has been shown to provide equivalent analgesia, while preserving quadriceps motor strength [8-10] and facilitating ambulation $[11,12]$.

The anterior cutaneous branches of the femoral nerve, the saphenous nerve, and branches of the obturator nerve travel through the adductor canal in the medial part of the thigh and innervate the surgical area involved in a medial UKA [13-15]. Previous studies focusing on TKA have suggested that single shot or continuous ACB added to a single-dose LIA can decrease postoperative pain and opioid consumption $[16,17]$. Only one study reported that a single shot $\mathrm{ACB}$ given preoperatively may provide equivalent analgesia after medial UKA when compared with psoas compartment block [18]. Furthermore, no studies have reported the effect of continuous ACB combined with single-dose local infiltration analgesia (LIA) as a multimodal analgesic regimen after medial UKA.

Therefore, this prospective, randomized, double-blind, placebo-controlled trial compared the effects of continuous $\mathrm{ACB}$ added to an intraoperative single-dose LIA after medial UKA. We hypothesized that a continuous infusion $\mathrm{ACB}$, in addition to LIA, would lower pain scores with movement at $24 \mathrm{~h}$ after surgery (primary outcome). We also hypothesized that this would improve serial pain scores, preserve quadriceps motor strength during physiotherapy, and facilitate ambulation within $48 \mathrm{~h}$ after surgery (secondary outcomes).

\section{Methods}

\section{Ethics and registration}

Approval was obtained from the Institutional Review Board of Xuanwu Hospital, Capital Medical University, code: $2017(074)$. The study was prospectively registered at Chictr.org.cn (code: ChiCTR-IOR-16008720) on June 25,2016 , and written informed consent was obtained from all participants before enrollment.

\section{Patient inclusion and exclusion criteria}

This prospective, randomized, double-blind, placebocontrolled trial was conducted from March 2017 to February 2018. Patients between 55 and 75 years of age were included if they were scheduled for medial UKA under spinal anesthesia (SA) with the American Association of Anesthesiologists (ASA) physical status of I-II. Patients were excluded if they had a history of opioid addiction, allergy to any of the study medications, a contraindication to ACB (peripheral neuropathy and infection at the procedure site) and/or a contraindication to SA (coagulopathy and recent anti-coagulant medication use).

\section{Randomization and blinding}

Randomization was carried out using a computergenerated randomization list. Patients were randomized into two groups; one receiving $0.2 \%$ ropivacaine (Group $\mathrm{RP}$ ), and a control receiving normal saline (Group Con) via the adductor canal. Each patient received a consecutive study number and treatment assigned by the randomization list. The list was stored and only two nurses, who prepared the study medications were allowed access. They had no interaction with the patients. All other medical personnel, participants and outcome assessors were blinded to the interventions.

\section{Administration of anesthesia and surgical procedure}

All patients received spinal anesthesia through a median or para- median approach using a 26 or $27 \mathrm{G}$ Whitacre needle with $2.0 \mathrm{ml} 0.5 \%$ bupivacaine at the L3/4. Sedation with propofol and fluid therapy were administered intraoperatively by an anesthesiologist. Surgical technique was identical for all patients and all procedures were done in a bloodless field by use of a femoral tourniquet. Unless contraindicated, all patients were given oral preoperative multimodal analgesic medications including $400 \mathrm{mg}$ celecoxib and $1000 \mathrm{mg}$ acetaminophen, according to the patients' weight. Ondansetron $4 \mathrm{mg}$ intravenous injections were administered prophylactically to prevent postoperative nausea and vomiting.

\section{LIA and continuous ACB}

All patients received LIA, consisting of a total of $100 \mathrm{ml} 0.2 \%$ ropivacaine, $10 \mathrm{mg}$ oxycodone and $0.5 \mathrm{mg}$ adrenaline. All solutions were prepared under aseptic conditions. This is routinely performed by the surgeon for all medial UKAs before prosthesis implantation and wound closure. Using a similar method described previously [19, 20], $40 \mathrm{~mL}$ of the mixture was injected into the posterior capsule and the medial and lateral ligaments before inserting the components, Another $30 \mathrm{ml}$ was injected into the anterior capsule, the synovium and retinacular tissues after insertion of the implants. The remaining mixture was infiltrated into the infrapatellar fat 
pad and the subcutaneous tissues before the closure of wound.

Upon completion of the surgery, patients were transferred to the post-anesthesia care unit, where standard monitoring was provided and continuous $\mathrm{ACB}$ was performed before spinal anesthesia had worn off.

A total of $300 \mathrm{~mL}(280 \mathrm{ml}$ for infusion and a $20 \mathrm{ml}$ bolus injection) of study solution, either $0.2 \%$ ropivacaine or normal saline, was prepared by either of the two unblinded nurses immediately after surgery.

The adductor canal was identified at mid-thigh level under ultrasound guidance and an 18-gauge Pajunk needle was inserted into the canal. A $20 \mathrm{~mL}$ bolus of the study drug ( $0.2 \%$ ropivacaine or normal saline) was administered. A bolus injection of $20 \mathrm{~mL}$ is required to fill the canal without risking retrograde flow to the femoral triangle [13, 21]. A 22gauge Pajunk catheter was then placed through the needle and advanced a further $5 \mathrm{~cm}$ into the canal. The position was confirmed by ultrasound with a $2-3 \mathrm{~mL}$ injection of normal saline. Four hours after bolus injection, a continuous infusion by an electronic pump was activated at $6 \mathrm{~mL} / \mathrm{h}$ for $48 \mathrm{~h}$. If signs of irritation, allergy, or infection were observed at the catheter site, the intervention was stopped immediately and the patient was excluded from the study. The catheter was removed on postoperative day 2 following the afternoon physiotherapy session.

All patients received a multimodal pain regimen postoperatively: oral acetaminophen $1000 \mathrm{mg}$ and oral celecoxib 200 mg every $12 \mathrm{~h}$. In addition, rescue analgesics were available with oral fast-release oxycodone $\leq 10 \mathrm{mg}$ every $4 \mathrm{~h}$ or as needed. If intolerance of oral medication, the patient was given, IV morphine $2.5 \mathrm{mg}$ every 1 hour or as needed.

\section{Outcome measures}

Demographic data were collected preoperatively. The preoperative maximum range of knee motion was assessed. Surgical and spinal block duration, and the length of surgical incision were also recorded. Research personnel blinded to group assignment performed all pre- and postoperative assessments and data collection.

\section{Primary outcome}

The primary end point was pain scores with active knee flexion in the operated knee at $24 \mathrm{~h}$ after surgery. At the time of the assessment, patients were instructed to record their pain on NRS-11 [22]. The numeric rating scale (NRS) is a tool that allows patients to express their perceived pain, where 0 indicates no pain and 10 indicates the worst possible pain. The NRS-11 was explained to patients in great detail preoperatively.

\section{Secondary outcomes}

Pain scores using the NRS-11 and the numbers of patients with NRS $>3$ at $8,12,24$, and $48 \mathrm{~h}$ after surgery were measured at rest and with movement. Additionally, the investigators recorded the first time point of postoperative pain at rest greater than $3(\mathrm{NRS}>3)$, known as breakthrough pain. Opioid consumption during $0-24 \mathrm{~h}$ and 24 $48 \mathrm{~h}$ postoperatively was retrieved from the electronic medical record and oral oxycodone converted to IV morphine equivalents for analysis $[23,24]$. As for the ambulation ability assessments, patients were mobilized at least twice on postoperative day (POD) 1 and 2 with physical therapy assistance. During each physical therapy session, patients were asked to ambulate as far as possible. The total ambulated distance, measured in meters, was recorded by blinded outcome assessors. Quadriceps muscle strength was assessed at $4,8,12,24$, and $48 \mathrm{~h}$ postoperatively by blinded research personnel. Patients were asked to hold the affected limb up with the knee extended against resistance of the examiner and assigned a number using the manual muscle testing $(\mathrm{MMT})$ grading scale $(0=$ no contraction, $1=$ flicker of contraction, 2 = active movement with gravity eliminated, $3=$ active movement against gravity but not resistance, $4=$ active movement against gravity and some resistance and $5=$ normal strength). Moreover, nerve block and catheter related complications and patient satisfaction were also assessed at 24 and $48 \mathrm{~h}$ postoperatively and all patients were asked to give a dichotomous verbal assessment ("Satisfied" or "Unsatisfied") of the quality of analgesia.

\section{Statistical analysis}

Statistical analysis was performed using IBM SPSS 20 (IBM Corporation, Armonk, New York). According to a pilot study of 12 patients receiving LIA without continuous ACB in our hospital, the mean pain score on movement at $24 \mathrm{~h}$ after surgery was NRS $=4.8$ [SD, 2.6]. This value has been reported by other, similar studies $[19,25]$. Our study intervention was modelled after Andersen (2013), who used combined analgesia after TKA [26]. As a result of combined analgesia, we expected to see a decrease of $\geq 2$ NRS points on movement at $24 \mathrm{~h}$ postoperatively in the treatment group. A sample size of 38 patients (19 in each group) was required for a type I error of 0.05 and a power of $90 \%$. Taking into account a potential dropout rate of $20 \%$, we aimed to recruit 46 patients in this study. Unpaired t-tests were used for the statistical analyses and continuous variables are presented as mean (SD). Ordinal and non-normally distributed variables are expressed as median (range), and the Mann-Whitney U test was applied. Dichotomous data (gender, rate of patients with NRS $>3$ and patient satisfaction) were analyzed using the chi-square test or Fisher's exact test. A $p<0.05$ was considered to be statistically significant.

\section{Results}

Sixty patients were approached for participation in this study. Forty-six patients were finally included and randomized to the treatment group or control group. Forty- 
two patients completed the study and were analyzed for outcomes. Four subjects were excluded due to protocol violations (Fig. 1). Of the 4 subjects excluded, 3 subjects from both groups requested to withdraw from the study, and 1 subject from Group Con had pump failure during the night. Preoperative measurements and demographic data were similar between groups. Moreover, there was no difference between groups with respect to surgery and spinal block durations, or length of surgical incision $(P>0.05$, Table 1$)$.

The primary end point of pain scores with active knee flexion in the operated knee at $24 \mathrm{~h}$ after surgery was significantly reduced in Group RP compared with Group Con (3 [IQR, 2.75-4.25] vs 5 [IQR, 4-6], $P<0.001$ ) (Table 2). Furthermore, time until breakthrough pain $(\mathrm{NRS}>3$ ) was significantly longer in Group RP than that in Group Con (18.5 [IQR, 4-46] hours vs 10.0 [IQR, 3-24] hours, $P=0.002$ ) (Table 2). In addition, NRS pain scores at rest and with movement at 8, 12, 24 and $48 \mathrm{~h}$ after surgery (Figs. 2 and 3), and rate of patients with NRS $>3$ with movement within 24 and $48 \mathrm{~h}$ postoperatively were significantly lower in Group RP than in Group Con (Table 2) $(P<0.05)$. As for the consumption of IV morphine, there was no significant difference between groups $0-24 \mathrm{~h}$ after surgery. However, Group RP consumed significantly less IV morphine at $24-48 \mathrm{~h}$ postoperatively compared to Group Con $(15.64 \pm 10.53 \mathrm{mg}$ vs $27.15 \pm 21.46 \mathrm{mg}, p=0.039$ ) (Table 3).

There was no difference between groups for quadriceps muscle strength assessed at different postoperative time points $(P>0.05)$ (Fig. 4). However, the treatment group showed a statistically significant improvement in maximum distance ambulated compared with that of the control group on POD 1 and 2: $(37.3 \pm 32.2$ vs $19.7 \pm 22.1, \quad P=0.046 ; \quad 59.5 \pm 28.3$ vs $33.4 \pm 20.8, P=0.002$ ) (Table 2).

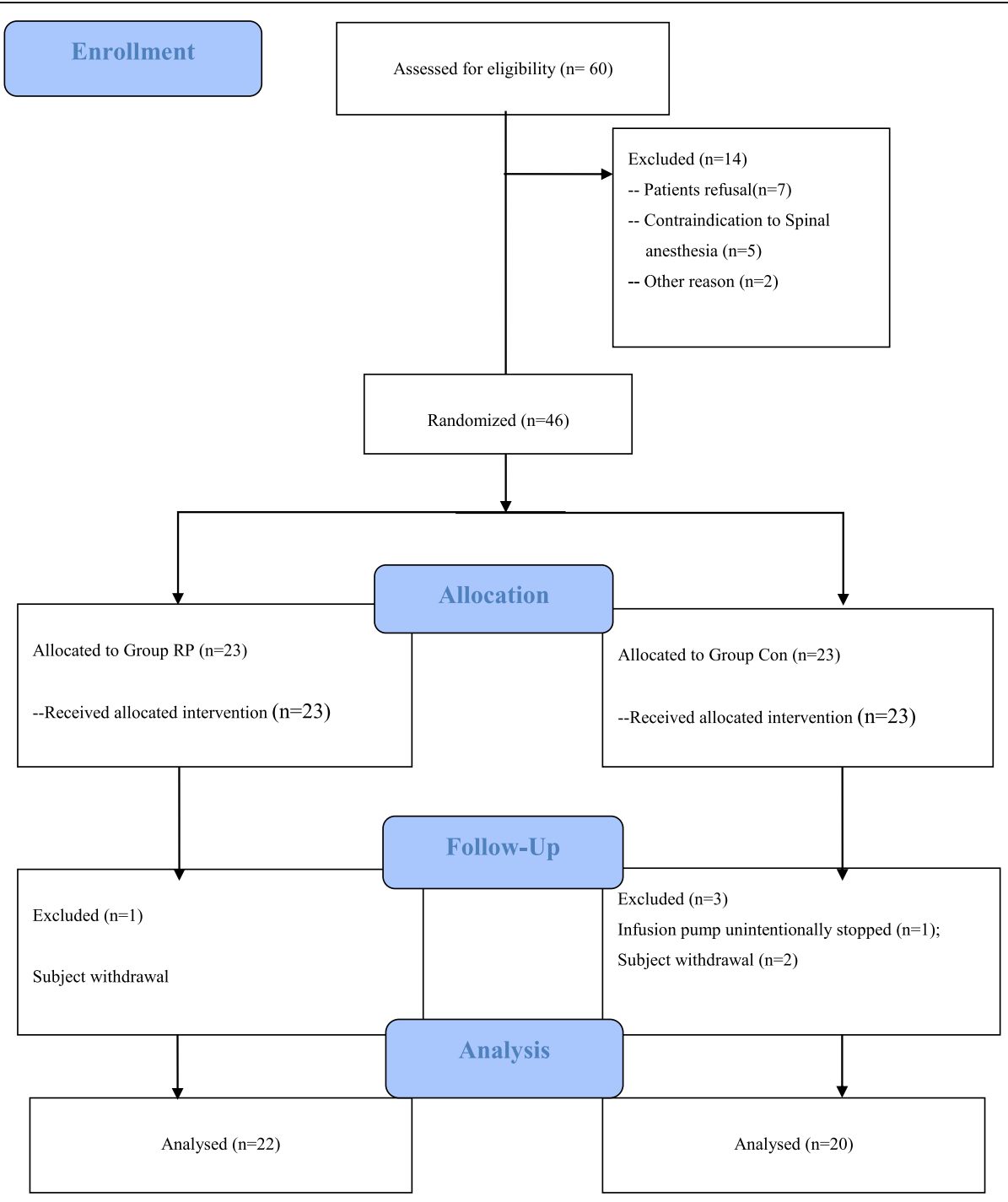

Fig. 1 Flow chart of the study 
Table 1 Demographics and baseline characteristics

\begin{tabular}{llll}
\hline & Group RP $(n=22)$ & Group Con $(n=20)$ & $P$ value \\
\hline Age, $(\mathrm{y})$ & $66.1 \pm 7.2$ & $67.9 \pm 6.5$ & 0.397 \\
Weight, $(\mathrm{kg})$ & $71.9 \pm 9.6$ & $67.3 \pm 10.9$ & 0.146 \\
Height, $(\mathrm{cm})$ & $162.27 \pm 4.92$ & $155.85 \pm 4.93$ & 0.221 \\
Body mass index, (kg/m2) & $27.3 \pm 3.7$ & $27.6 \pm 3.8$ & 0.829 \\
Sex, (male) & 5 & 4 & 0.578 \\
Duration of surgery, (min) & $136 \pm 22$ & $124 \pm 17$ & 0.058 \\
Duration of spinal block, (min) & $143 \pm 7$ & $140 \pm 9$ & 0.215 \\
Surgical incision length, (cm) & $13.4 \pm 3.0$ & $12.0 \pm 3.0$ & 0.097 \\
Range of motion before surgery, (degree) & $102 \pm 13$ & $102 \pm 16$ & 0.667 \\
\hline
\end{tabular}

Values are shown as mean \pm SD

In addition, there was no nerve block and catheter related complications to be reported in either groups, and no difference was found in patient analgesia satisfaction at 24 and $48 \mathrm{~h}$ postoperatively ( $86 \%$ vs $85 \%, P=0.617$; $81 \%$ vs $75 \%, P=0.437$ ) (Table 3 ).

\section{Discussion}

Our findings demonstrate that the addition of a continuous ACB to single-dose of LIA after medial UKA significantly reduced pain scores with knee movement at $24 \mathrm{~h}$ after surgery. This result is strengthened by the fact that the time until breakthrough pain was significantly longer in Group RP. Furthermore, better pain relief was demonstrated by the fact that patients in the treatment group were better able to ambulate on POD 1 and 2 .

Previous studies have demonstrated improved pain relief and decreased opioid consumption in patients receiving LIA after knee arthroplasty [27, 28]. However, periarticular infiltration analgesic regimens that infiltrate anterior, medial, and posterior compartments of the knee are reported to only last 6 to $12 \mathrm{~h}[29,30]$, which is consistent with our observation from the time until breakthrough pain.
Femoral nerve block when applied as part of multimodal analgesic management for patients undergoing TKA has been reported to decrease opioid consumption and lower postoperative pain scores [5]. Despite the improved analgesic outcomes, prolonged motor block and quadriceps weakness from femoral nerve block inhibit "fast track" rehabilitation [31, 32]. NRS pain scores on movement (knee flexion) at $24 \mathrm{~h}$ was chosen as the primary outcome in this study. Assessing pain at this time point is important for determining adequate analgesia for starting physical therapy, as the first physical therapy session was initiated $24 \mathrm{~h}$ postoperatively. In addition, previous studies have suggested that movement pain is more important than rest pain [33]. In this study, the duration of spinal anesthesia with $10 \mathrm{mg}$ bupivacaine was approximately $15 \mathrm{~min}$ more than surgical duration in Group Con and 6 min more than surgical duration in Group RP. Moreover, the first pain assessment was initiated at $8 \mathrm{~h}$ postoperatively. Therefore, spinal anesthesia, which impairs the quality of clinical assessment could be ignored.

Our results support the addition of a continuous ACB to a single-dose LIA after medial UKA to supply sufficient

Table 2 Primary endpoint, percentage of patients with NRS pain score $>3$ within 24 and $48 \mathrm{~h}$ postoperatively, first time point of breakthrough pain and ambulated distance postoperatively

\begin{tabular}{|c|c|c|c|}
\hline & Group RP $n=22$ & Group Con $n=20$ & $\overline{p \text {-value }}$ \\
\hline NRS durimg active knee flexion at $24 \mathrm{~h}$ postoperatively & $3(2-4)$ & $5(4-6)$ & $<0.001$ \\
\hline \multicolumn{4}{|l|}{ Patients with NRS>3 at rest. No. (\%) } \\
\hline within $24 \mathrm{~h}$ postoperatively & $2(3)$ & $6(10)$ & 0.150 \\
\hline within $48 \mathrm{~h}$ postoperatively & $2(2)$ & $8(10)$ & 0.049 \\
\hline \multicolumn{4}{|l|}{ Patients with NRS>3 with movement. No. (\%) } \\
\hline within $24 \mathrm{~h}$ postoperatively & $8(12)$ & $39(65)$ & $<0.001$ \\
\hline within $48 \mathrm{~h}$ postoperatively & $17(19)$ & $54(68)$ & $<0.001$ \\
\hline Time to breakthrough pain (NRS > 3), (hours) & $10(3-24)$ & $18(4-46)$ & 0.002 \\
\hline Ambulated distance on POD 1, (meters) & $37.3 \pm 32.2$ & $19.7 \pm 22.1$ & 0.046 \\
\hline Ambulated distance on POD 2, (meters) & $59.5 \pm 28.3$ & $33.4 \pm 20.8$ & 0.002 \\
\hline
\end{tabular}

Data are shown as counts, median (interquartile range) or a mean \pm SD; NRS = Numeric rating scale (for assessment of pain intensity) 


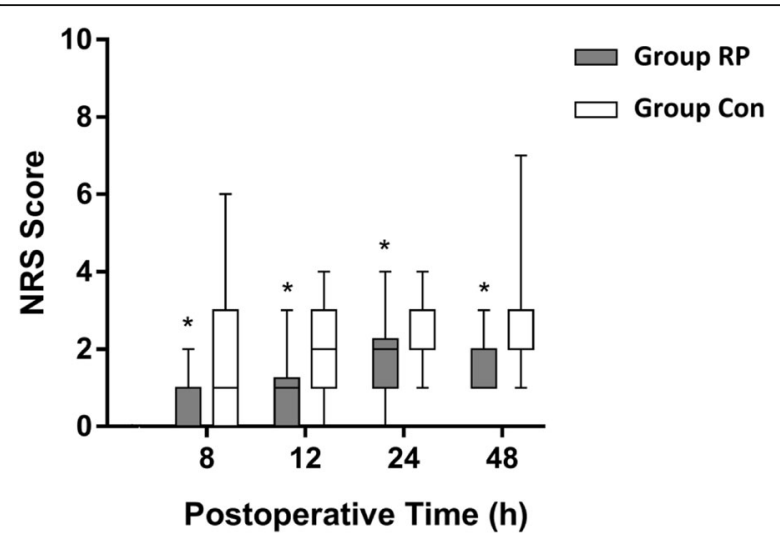

Fig. 2 Pain assessment at different time points postoperatively at rest. Data are expressed as median (horizontal bar) with 25th-75th (box) percentile and minimum to maximum (whiskers). ${ }^{*} P<0.05$

analgesia, especially with movement, and help with ambulation after the day of surgery. Simple time-by-time comparisons for the repeated pain measurements, strongly inflated the type-I error. As a result, we transformed the data into number of relevant events $(\mathrm{NRS}>3)$ and compared the rates after surgery. We found the major difference of pain scores between groups occurred during movement. Similar to this study, previous studies had suggested that continuous ACB combined with single dose LIA can reduce pain scores (at rest and with movement) and opioid consumption after total knee replacement [26, 34]. Andersen et al. reported that saphenous nerve block with single-dose LIA offered better pain relief on the day of surgery than LIA alone after TKA, but no validated physiotherapy testing was used to compare the groups in that study. Conversely, Gudmundsdottir and Franklin reported that there is no pain related benefit to be acquired from adding an ACB to a single-dose LIA during physiotherapy session on POD

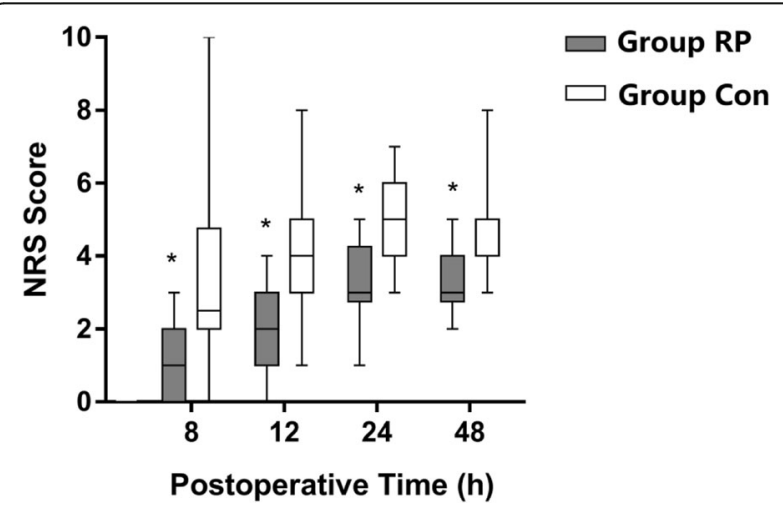

Fig. 3 Pain assessment at different time points postoperatively with movement. Data are expressed as median (horizontal bar) with 25th -75th (box) percentile and minimum to maximum (whiskers). ${ }^{*} P<0.05$
1 after TKA [17]. The main reason our results differ relates to the type of knee surgery itself. Total knee arthroplasty is invasive and more painful following surgery, leading to the need for more potent pain relief postoperatively. UKA is characterized by short incisions, less osteotomy and is capable of rapid recovery [35]. However pain is still an important issue in early postoperative functional rehabilitation [1, 36], which was consistent with what we found when comparing the rate of patients with NRS $>3$ with movement in control group. In this study, the mean surgical incision in both groups was over $12 \mathrm{~cm}$ long, similar to conventional surgery. However, it has been reported that even with minimally invasive surgery of UKA (an 8 to 10 $\mathrm{cm}$-long medial parapatellar skin incision), pain scores and functional outcomes were not improve by using LIA alone [37]. Considering the surgical area of nerve innervation in medial UKA, continuous ACB may be uniquely suited to provide postoperative analgesia. Therefore, it is readily explained that continuous ACB plus single shot LIA can reduce pain scores at rest and with movement after surgery, and facilitate ambulation as shown in this study.

Patient satisfaction was assessed as "satisfied" or "unsatisfied" at 24 and $48 \mathrm{~h}$ postoperatively. Essving (2009) reported that pain scores at rest and with movement were acceptable for patients who underwent medial UKA with intra-articular LIA combined with perioperative oral analgesics within $24 \mathrm{~h}$ postoperatively [19]. This is similar to the control group in this study. Therefore we are not surprised that there is no difference in patient satisfaction at $24 \mathrm{~h}$ after surgery. Furthermore, there was no difference in IV rescue morphine consumption during 0-24h postoperatively, although NRS pain scores within $24 \mathrm{~h}$ after surgery were significantly lower in Group RP. However, during the $24-48 \mathrm{~h}$ postoperative period, intraarticular LIA had completely worn off, leading to an increase in overall pain scores seen in Group Con and likely had negative effects on physiotherapy after post-operative day 1 . Increased pain likely led to the increase in IV rescue morphine consumption seen in Group Con during this time period. Therefore, patient satisfaction at $48 \mathrm{~h}$ postoperatively in Group Con was lower than in Group RP, although there was no statistical difference.

Motor block caused by peripheral nerve block in the lower extremities is a well-known adverse effect that compromises rehabilitation and even causes a risk of falling [38, 39]. There are case reports to suggest that $\mathrm{ACB}$ can affect quadriceps muscle strength, which can limit ambulation abilities [40, 41], however, this seems to be rare. In our study, at $48 \mathrm{~h}$ after surgery, there was no difference in quadriceps muscle strength between 
Table 3 Morphine consumption, patient satisfaction and catheter related infection after surgery

\begin{tabular}{llll}
\hline & Group RP $(n=22)$ & Group Con $(n=20)$ & \\
\hline IV morphine consumption, $(\mathrm{mg})$ & & $17.8 \pm 7.41$ & 0.063 \\
0-24 h postoperatively & $13.82 \pm 5.50$ & $27.15 \pm 21.46$ \\
24-48 h postoperatively & $15.64 \pm 10.53$ & & \\
Satisfied patients, No. (\%) & & $17(85)$ \\
24 h postoperatively & $19(86)$ & $15(75)$ & 0.039 \\
48 h postoperatively & $18(81)$ & 0 & 0.437 \\
Nerve blocking and catheter related complications, No. (\%) & 0 & & - \\
\hline
\end{tabular}

Values are shown as mean \pm SD or frequency (\%)

groups, which likely facilitated patients' early ambulation. From pain evaluation scores at different time points after surgery, it is not difficult to understand why the ambulated distance of patients in the treatment group was much longer compared with the control group. Pain was better managed during the first $48 \mathrm{~h}$ after surgery and the quadriceps muscle strength was well maintained.

The use of an invasive placebo may raise ethical concerns for some readers. Although it has been debated that invasive placebos are not consistent with ethical practice [42, 43], there is no consensus on the issue within the research community, nor are there uniform standards between ethics committees. The current study was approved by the Institutional Review Board of Xuanwu Hospital, Capital Medical University and all study participants provided informed consent. We assigned blind investigators to assess complications of nerve block in both groups. No patient in either group experienced temporary or permanent complications from the invasive placebo or treatment.

Although there are limitations to a continuous catheter approach [44, 45], such as patients' unintentional catheter removal, continuous ACB can provide a more prolonged analgesic effect compared with the singledose method, facilitating rehabilitation on POD 1 and 2 . In addition, there was no catheter related complications

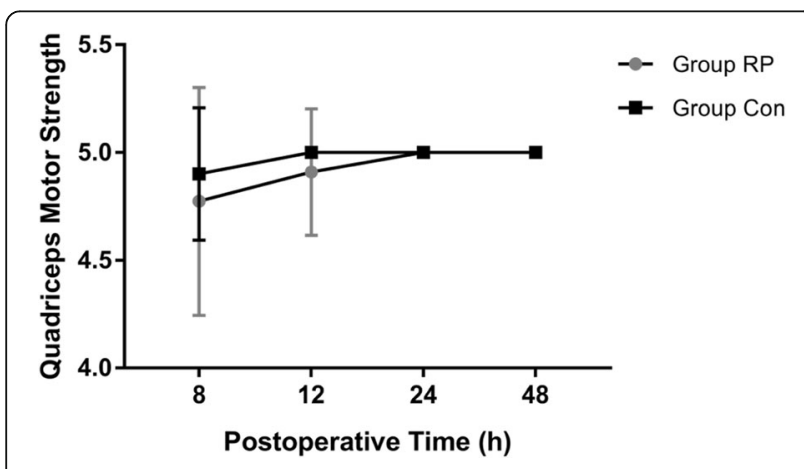

Fig. 4 Quadriceps muscle strength assessment postoperatively. Data are expressed as mean (SD) in either group, and no patient complained of the inconvenience of a portable infusion device.

In this study, the initial dose of ropivacaine for LIA was less than the maximal dose $(225 \mathrm{mg})$ indicated by drug label [46], however, when combined with ACB bolus, the total dose $(240 \mathrm{mg})$ of ropivacaine was slightly higher than recommended. However, previous studies have shown that injecting a much higher dose of ropivacaine in intra-articular LIA, than used in this study, is safe, with plasma levels below systemic toxic threshold [47-50]. Moreover, there was a $60 \mathrm{~min}$ interval between injections, which reduced plasma levels. This procedure is considered safe, while also aiming to maximize the duration of the block as safely as possible.

There are several limitations to this study. In order to guarantee all staff and study participants were blinded to the treatment group, we did not assess the success rate of the block. In that way, we cannot confirm that the blocks were all functioning accurately. However, Saranteas et al. has shown about 95\% success rate of ACB using a similar approach [44]. In addition, no professional physiotherapists took part in this study, resulting in the inability to record ambulation ability. However, the strengths of our study include, effective randomization, the successful blinding process, and consistent management in standardizing the pre- and postoperative medication. It also was sufficiently powered for the primary end point. Finally, we did not measure total and free plasma concentrations of ropivacaine following LIA and ACB. This would have allowed us to be certain that systemic toxic thresholds were not reached. Although these values were not measured, patients were monitored closely for signs of toxic symptoms which no patient experienced.

\section{Conclusions}

This study suggests that continuous ACB added to single-dose LIA provides sufficient pain treatment after medial UKA and promotes early ambulation. Further studies are needed to address the additional effects that ACB provides to LIA on the day of surgery with a primary focus on ambulation abilities. 


\section{Abbreviations}

ACB: Adductor Canal Block; ASA: American Association of Anesthesiologists; FNB: Femoral Nerve Blockade; LIA: Local Infiltration Anesthesia; MMT: Manual Muscle Testing; NRS-11: Numeric Rating Scale; PNB: Peripheral Nerve Blocks; SA: Spinal Anesthesia; TKA: Total Knee Arthroplasty; UKA: Unicondylar Knee Arthroplasty

\section{Acknowledgements}

We would like to thank Dr. Zheng Li and Dr. Shuai An for their invaluable contributions during this collaboration.

\section{Prior presentation}

Interim data from this work was presented as a Poster at the 36th Annual European Society of Regional Anesthesia \& Pain Therapy in Switzerland, September 13-16, 2017

\section{Authors' contributions}

FL designed the study, conducted the study, and analyzed the data. YYS analyzed and interpreted the patients' data regarding this study. YHM and TZ performed the patients' anesthesia and continuous adductor canal block, and GLC was a major orthopedist performing surgeries. FL and NP were major contributor in writing the manuscript. TLW helped in designing the study, analyzing the data and revising the manuscript. All authors read and approved the final manuscript.

\section{Funding}

This study received funding from Beijing Municipal Administration of Hospitals' Ascent Plan (Code: DFL20150802), Acknowledgements-Beijing Municipal Commission of Health and Family Planning from National Clinical Research Center for Geriatric Disorders (Code: No. PXM2017_026283_000002), Beijing Municipal Administration of Hospitals Clinical Medicine Development of Special Funding Support (Code: ZYLX201706) and Beijing Municipal Administration of Hospitals Clinical Medicine Development of Special Funding Support (Code: ZYLX201813). The funders are Dr. Tianlong Wang. He helped in designing the study, analyzing the data and revising the manuscript.

\section{Availability of data and materials}

The datasets used and/or analysed during the current study are available from the corresponding author on reasonable request.

\section{Ethics approval and consent to participate}

Approval was obtained from the Institutional Review Board of Xuanwu Hospital, Capital Medical University, code: 2017(074). The study was prospectively registered at Chictr.org.cn (code: ChiCTR-IOR-16008720) on June 25, 2016, and written informed consent was obtained from all participants before enrollment.

\section{Consent for publication}

Not applicable.

\section{Competing interests}

The authors declare that they have no competing interests.

\section{Author details}

'Department of Anesthesiology Xuanwu Hospital, Capital Medical University, No.45, Changchun Street, Beijing 100053, China. ${ }^{2}$ Department of Anesthesiology, Peking University International Hospital, Beijing, China. ${ }^{3}$ Department of Orthopedics Xuanwu Hospital, Capital Medical University, Beijing, China. ${ }^{4}$ Department of Critical Care Medicine St. Michael's Hospital, University of Toronto, Toronto, Canada.

\section{Received: 26 January 2019 Accepted: 19 June 2019}

\section{Published online: 29 June 2019}

\section{References}

1. Lygre SH, Espehaug B, Havelin LI, Furnes O, Vollset SE. Pain and function in patients after primary unicompartmental and total knee arthroplasty. J Bone Joint Surg Am. 2010;92:2890-7.

2. Husted H, Lunn TH, Troelsen A, Gaarn-Larsen L, Kristensen BB, Kehlet H. Why still in hospital after fast-track hip and knee arthroplasty? Acta Orthop. 2011; 82:679-84.
3. Vendittoli PA, Makinen P, Drolet P, Lavigne M, Fallaha M, Guertin MC, Varin F. A multimodal analgesia protocol for total knee arthroplasty. A randomized, controlled study. J Bone Joint Surg Am. 2006;88:282-9.

4. Webb CA, Mariano ER. Best multimodal analgesic protocol for total knee arthroplasty. Pain Manag. 2015;5:185-96.

5. Paul JE, Arya A, Hurlburt L, Cheng J, Thabane L, Tidy A, Murthy Y. Femoral nerve block improves analgesia outcomes after total knee arthroplasty: a meta-analysis of randomized controlled trials. Anesthesiology. 2010;113: 1144-62.

6. Zhang Z, Shen B. Effectiveness and weakness of local infiltration analgesia in total knee arthroplasty: a systematic review. J Int Med Res. 2018;46(12): 4874-84. https://doi.org/10.1177/0300060518799616.

7. Johnson RL, Kopp SL, Hebl JR, Erwin PJ, Mantilla CB. Falls and major orthopaedic surgery with peripheral nerve blockade: a systematic review and meta-analysis. Br J Anaesth. 2013;110:518-28.

8. Koh IJ, Choi YJ, Kim MS, Koh HJ, Kang MS, In Y. Femoral nerve block versus Adductor Canal block for analgesia after Total Knee arthroplasty. Knee Surg Relat Res. 2017;29:87-95.

9. Jaeger $\mathrm{P}$, Nielsen ZJ, Henningsen MH, Hilsted KL, Mathiesen O, Dahl JB. Adductor canal block versus femoral nerve block and quadriceps strength: a randomized, double-blind, placebo-controlled, crossover study in healthy volunteers. Anesthesiology. 2013;118:409-15.

10. Kim DH, Lin Y, Goytizolo EA, Kahn RL, Maalouf DB, Manohar A, Patt ML, Goon AK, Lee YY, Ma Y, et al. Adductor canal block versus femoral nerve block for total knee arthroplasty: a prospective, randomized, controlled trial. Anesthesiology. 2014;120:540-50.

11. Machi AT, Sztain JF, Kormylo NJ, Madison SJ, Abramson WB, Monahan AM, Khatibi B, Ball ST, Gonzales FB, Sessler DI, et al. Discharge readiness after Tricompartment Knee arthroplasty: Adductor Canal versus femoral continuous nerve blocks-a dual-center, randomized trial. Anesthesiology. 2015;123:444-56.

12. Grevstad U, Mathiesen $O$, Valentiner LS, Jaeger $P$, Hilsted KL, Dahl JB. Effect of adductor canal block versus femoral nerve block on quadriceps strength, mobilization, and pain after total knee arthroplasty: a randomized, blinded study. Reg Anesth Pain Med. 2015;40:3-10.

13. Lund J, Jenstrup MT, Jaeger P, Sorensen AM, Dahl JB. Continuous adductorcanal-blockade for adjuvant post-operative analgesia after major knee surgery: preliminary results. Acta Anaesthesiol Scand. 2011;55:14-9.

14. Burckett-St Laurant D, Peng P, Giron Arango L, Niazi AU, Chan WW, Agur A, Perlas $A$. The nerves of the Adductor Canal and the innervation of the Knee: an anatomic study. Reg Anesth Pain Med. 2016;41:321-7.

15. Franco CD, Buvanendran A, Petersohn JD, Menzies RD, Menzies LP. Innervation of the anterior capsule of the human Knee: implications for radiofrequency ablation. Reg Anesth Pain Med. 2015;40:363-8.

16. Nader A, Kendall MC, Manning DW, Beal M, Rahangdale R, Dekker R, De Oliveira GS Jr, Kamenetsky E, McCarthy RJ. Single-dose Adductor Canal block with local infiltrative analgesia compared with local infiltrate analgesia after Total Knee arthroplasty: a randomized, double-blind, placebocontrolled trial. Reg Anesth Pain Med. 2016:41:678-84.

17. Gudmundsdottir S, Franklin JL. Continuous adductor canal block added to local infiltration analgesia (LIA) after total knee arthroplasty has no additional benefits on pain and ambulation on postoperative day 1 and 2 compared with LIA alone. Acta Orthop. 2017:88:537-42.

18. Henshaw DS, Jaffe JD, Reynolds JW, Dobson S, Russell GB, Weller RS. An evaluation of ultrasound-guided Adductor Canal blockade for postoperative analgesia after medial Unicondylar Knee arthroplasty. Anesth Analg. 2016;122:1192-201.

19. Essving P, Axelsson K, Kjellberg J, Wallgren O, Gupta A, Lundin A. Reduced hospital stay, morphine consumption, and pain intensity with local infiltration analgesia after unicompartmental knee arthroplasty. Acta Orthop. 2009:80:213-9.

20. Sawhney M, Mehdian H, Kashin B, Ip G, Bent M, Choy J, McPherson M Bowry R. Pain after unilateral Total Knee arthroplasty: a prospective randomized controlled trial examining the analgesic effectiveness of a combined Adductor Canal peripheral nerve block with periarticular infiltration versus Adductor Canal nerve block alone versus periarticular infiltration alone. Anesth Analg. 2016;122:2040-6.

21. Andersen $\mathrm{HL}$, Andersen $\mathrm{SL}$, Tranum-Jensen J. The spread of injectate during saphenous nerve block at the adductor canal: a cadaver study. Acta Anaesthesiol Scand. 2015:59:238-45.

22. Hjermstad MJ, Fayers PM, Haugen DF, Caraceni A, Hanks GW, Loge JH, Fainsinger R, Aass N, Kaasa S. European palliative care research C: studies comparing numerical rating scales, verbal rating scales, and visual analogue 
scales for assessment of pain intensity in adults: a systematic literature review. J Pain Symptom Manag. 2011;41:1073-93.

23. Treillet $E$, Laurent $S$, Hadjiat $Y$. Practical management of opioid rotation and equianalgesia. J Pain Res. 2018;11:2587-601.

24. Golembiewski J. Equianalgesic dosing: implications for the perianesthesia setting. J Perianesth Nurs. 2002;17:341-3.

25. Berninger MT, Friederichs J, Leidinger W, Augat P, Buhren V, Fulghum C, Reng W. Effect of local infiltration analgesia, peripheral nerve blocks, general and spinal anesthesia on early functional recovery and pain control in unicompartmental knee arthroplasty. BMC Musculoskelet Disord. 2018;19:249.

26. Andersen HL, Gyrn J, Moller L, Christensen B, Zaric D. Continuous saphenous nerve block as supplement to single-dose local infiltration analgesia for postoperative pain management after total knee arthroplasty. Reg Anesth Pain Med. 2013;38:106-11.

27. Mont MA, Beaver WB, Dysart SH, Barrington JW, Del Gaizo DJ. Local infiltration analgesia with liposomal bupivacaine improves pain scores and reduces opioid use after Total Knee arthroplasty: results of a randomized controlled trial. J Arthroplast. 2018;33:90-6.

28. Sadigursky D, Simoes DP, de Albuquerque RA, Silva MZ, Fernandes RJC, Colavolpe PO. Local periarticular analgesia in Total Knee arthroplasty. Acta Ortop Bras. 2017;25:81-4

29. Kehlet $\mathrm{H}$, Andersen LO. Local infiltration analgesia in joint replacement: the evidence and recommendations for clinical practice. Acta Anaesthesiol Scand. 2011;55:778-84.

30. Busch CA, Shore BJ, Bhandari R, Ganapathy S, MacDonald SJ, Bourne RB, Rorabeck $\mathrm{CH}, \mathrm{McC}$ alden RW. Efficacy of periarticular multimodal drug injection in total knee arthroplasty. A randomized trial. J Bone Joint Surg Am. 2006:88:959-63.

31. Sharma S, lorio R, Specht LM, Davies-Lepie S, Healy WL. Complications of femoral nerve block for total knee arthroplasty. Clin Orthop Relat Res. 2010;468:135-40.

32. Turbitt LR, McHardy PG, Casanova M, Shapiro J, Li L, Choi S. Analysis of inpatient falls after Total Knee arthroplasty in patients with continuous femoral nerve block. Anesth Analg. 2018;127:224-7.

33. Breivik H, Borchgrevink PC, Allen SM, Rosseland LA, Romundstad L, Hals EK, Kvarstein G, Stubhaug A. Assessment of pain. Br J Anaesth. 2008;101:17-24.

34. Hanson NA, Allen CJ, Hostetter LS, Nagy R, Derby RE, Slee AE, Arslan A, Auyong DB. Continuous ultrasound-guided adductor canal block for total knee arthroplasty: a randomized, double-blind trial. Anesth Analg. 2014;118:1370-7.

35. Price AJ, Webb J, Topf H, Dodd CA, Goodfellow JW, Murray DW, Oxford H, Knee G. Rapid recovery after oxford unicompartmental arthroplasty through a short incision. J Arthroplast. 2001;16:970-6.

36. Lum ZC, Lombardi AV, Hurst JM, Morris MJ, Adams JB, Berend KR. Early outcomes of twin-peg mobile-bearing unicompartmental knee arthroplasty compared with primary total knee arthroplasty. Bone Joint J. 2016;98-B(10 Supple B):28-33.

37. Essving P, Axelsson K, Otterborg L, Spannar H, Gupta A, Magnuson A, Lundin A. Minimally invasive surgery did not improve outcome compared to conventional surgery following unicompartmental knee arthroplasty using local infiltration analgesia: a randomized controlled trial with 40 patients. Acta Orthop. 2012;83:634-41.

38. Ilfeld BM, Duke KB, Donohue MC. The association between lower extremity continuous peripheral nerve blocks and patient falls after knee and hip arthroplasty. Anesth Analg. 2010;111:1552-4.

39. Lovald ST, Ong KL, Lau EC, Joshi GP, Kurtz SM, Malkani AL. Readmission and complications for catheter and injection femoral nerve block administration after Total Knee arthroplasty in the Medicare population. J Arthroplast. 2015;30:2076-81.

40. Neal JM, Salinas FV, Choi DS. Local anesthetic-induced myotoxicity after continuous Adductor Canal block. Reg Anesth Pain Med. 2016;41:723-7.

41. Chen J, Lesser JB, Hadzic A, Reiss W, Resta-Flarer F. Adductor canal block can result in motor block of the quadriceps muscle. Reg Anesth Pain Med. 2014:39:170-1

42. McGuirk S, Fahy C, Costi D, Cyna AM. Use of invasive placebos in research on local anaesthetic interventions. Anaesthesia. 2011;66:84-91.

43. Sites BD, Neal JM. Placebo or intervention? Is it all a sham? Anaesthesia. 2011;66:73-5

44. Saranteas T, Anagnostis G, Paraskeuopoulos T, Koulalis D, Kokkalis Z, Nakou M, Anagnostopoulou S, Kostopanagiotou G. Anatomy and clinical implications of the ultrasound-guided subsartorial saphenous nerve block. Reg Anesth Pain Med. 2011;36:399-402.

45. Iffeld BM. Continuous peripheral nerve blocks: an update of the published evidence and comparison with novel, alternative analgesic modalities. Anesth Analg. 2017;124:308-35.
46. Ropivacainehydro chloride Injection. DXY Drugs Information Database. http://drugs.dxy.cn/drug/91500.htm. Accessed 1 June 2016.

47. Bakker SMK, Fenten MGE, Touw DJ, van den Bemt BJF, Heesterbeek PJC, Scheffer GJ, Stienstra R. Pharmacokinetics of 400 mg locally infiltrated Ropivacaine after Total Knee arthroplasty without perioperative tourniquet use. Reg Anesth Pain Med. 2018;43:699-704.

48. Fenten MG, Bakker SM, Touw DJ, van den Bemt BJ, Scheffer GJ, Heesterbeek PJ, Stienstra R. Pharmacokinetics of $400 \mathrm{mg}$ ropivacaine after periarticular local infiltration analgesia for total knee arthroplasty. Acta Anaesthesiol Scand. 2017:61:338-45

49. Miller RJ, Cameron AJ, Dimech J, Orec RJ, Lightfoot NJ. Plasma Ropivacaine concentrations following local infiltration analgesia in Total Knee arthroplasty: a pharmacokinetic study to determine safety following fixeddose administration. Reg Anesth Pain Med. 2018;43:347-51.

50. van Haagen MHM, Verburg $H$, Hesseling $B$, Coors $L$, van Dasselaar NT, Langendijk PNJ, Mathijssen NMC. Optimizing the dose of local infiltration analgesia and gabapentin for total knee arthroplasty, a randomized single blind trial in 128 patients. Knee. 2018;25:153-60.

\section{Publisher's Note}

Springer Nature remains neutral with regard to jurisdictional claims in published maps and institutional affiliations.
Ready to submit your research? Choose BMC and benefit from:

- fast, convenient online submission

- thorough peer review by experienced researchers in your field

- rapid publication on acceptance

- support for research data, including large and complex data types

- gold Open Access which fosters wider collaboration and increased citations

- maximum visibility for your research: over $100 \mathrm{M}$ website views per year

At BMC, research is always in progress.

Learn more biomedcentral.com/submissions 